\title{
Lung cancer screening: Dollars and scents
}

\author{
Sudish C. Murthy, MD, PhD
}

\author{
From the Department of Thoracic and Cardiovascular Surgery, Heart and Vascular Institute, Cleveland Clinic, \\ Cleveland, Ohio. \\ Supported in part by the Daniel and Karen Lee Endowed Chair in Thoracic Surgery, held by S.C.M. \\ Disclosures: Author has nothing to disclose with regard to commercial support. \\ Received for publication Sept 22, 2015; accepted for publication Sept 23, 2015. \\ Address for reprints: Sudish C. Murthy, MD, PhD, Section Head, General Thoracic Surgery, Department of Thoracic \\ and Cardiovascular Surgery, 9500 Euclid Ave, Desk J4-1, Cleveland, OH 44195 (E-mail: murthys1@ @cf.org). \\ J Thorac Cardiovasc Surg 2015;150:1525 \\ $0022-5223 / \$ 36.00$ \\ Copyright (C) 2015 by The American Association for Thoracic Surgery \\ http://dx.doi.org/10.1016/j.jtcvs.2015.09.093
}

The recently completed National Lung Cancer Screening trial suggests a definitive role for computed tomographic (CT) screening in managing non-small cell lung cancer (NSCLC). Patients at high risk for lung cancer appear to receive a tangible benefit from screening, with perhaps as much as a $20 \%$ reduction in lung cancer-specific mortality. ${ }^{1}$ In a field where survival has hardly changed in 20 years, this is headline news for patient and doctor alike. Unfortunately, when throwing out a large, relatively unfocused net as a filter, you ultimately catch a bunch of other things that must be individually adjudicated before being either thrown back into the ocean or kept, and herein lies the financial rub that threatens adoption of this screen.

In this issue of the Journal, Schumer and colleagues ${ }^{2}$ have proposed an alternative screen that uses exhaled volatile carbonyl compounds as a potential cost-reducing strategy for NSCLC screening. The discovery of a "nose print" for NSCLC is not new. ${ }^{3}$ But, as with most good ideas, technology eventually finds a way to move a complex, important, laboratory finding into the translational realm. And when a financial interest is involved, the trip from Bunsen burner to patient is swift. Consequently, despite the sophisticated silicon microchip and mass spectrometry analysis necessary to generate the exhaled gas profile, I suspect that costs are front and center.

Of course, supporting data are always helpful, and to this end Schumer and colleagues ${ }^{2}$ demonstrate a promising sensitivity and specificity profile for lung cancer detection by means of exhaled gas. As is seemingly always the case, sensitivity and specificity move in opposite directions as varying constraints are applied to the data set, and we are left wondering whether as a screen we are better off with a lower false-positive rate or a lower false-negative rate. I suspect that the answer depends on whether you are getting screened or paying for the screen.

One issue that has been overlooked when suggesting that a rigorously tested standard (CT screen for NSCLC) be replaced with a completely new one is whether there is room to make CT screening better (we already know that it works!). CT screening for NSCLC generates an enormous number of false-positive findings, even in high-risk

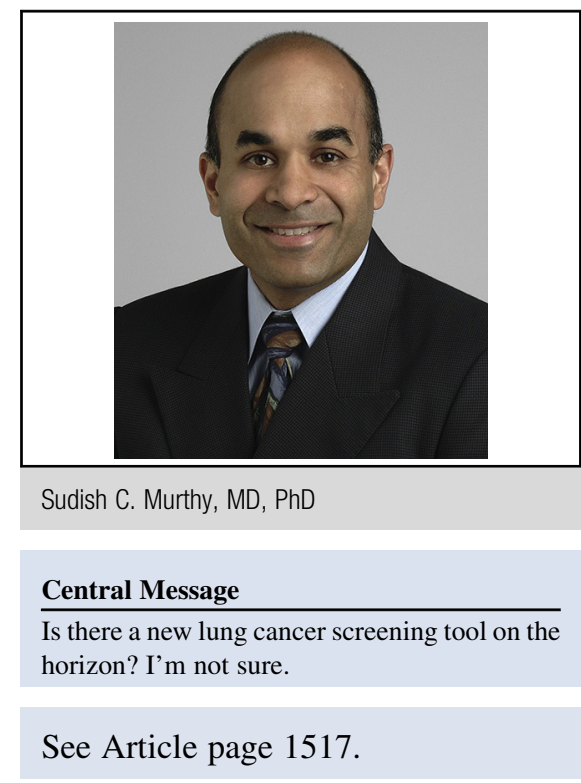

populations, with perhaps $25 \%$ of screened patients having an abnormal scan. But is this really where we stop? Of those $25 \%$, many have multiple small nodules, calcified nodules, nonspiculated nodules, intraparenchymal lymph nodes, or even scars. Our radiologists (and thoracic surgeons) are adept at identifying high-risk (true cancer) nodules, and much of the white noise can be easily filtered out. Simple radiographic assessments such as spiculation, location, calcium distribution, size, ground-glass opacity ratio, tumor disappearance rate, and consolidation diameter may, in the near future, not be used simply to predict cancer of a screened nodule but to provide a prognosis. ${ }^{4}$

There is little doubt that the "scent of cancer" will be an important diagnostic tool for NSCLC. Where it will fit in is unclear, but right now, despite cost concerns, the chest CT reigns supreme, and I doubt that a hostile takeover is looming in the immediate future.

\section{References}

1. Aberle DR, Adams AM, Berg CD, Black WC, Clapp JD, Fagerstrom RM, et al; National Lung Screening Trial Research Team. Reduced lung-cancer mortality with low-dose computed tomographic screening. N Engl J Med. 2011;365: 395-409.

2. Schumer EM, Trivedi JR, van Berkel V, Black MC, Li M, Fu XA, et al. High sensitivity for lung cancer detection using analysis of exhaled carbonyl compounds. $J$ Thorac Cardiovasc Surg. 2015;150:1517-24.

3. Mazzone P. Analysis of volatile organic compounds in the exhaled breath for the diagnosis of lung cancer. J Thorac Oncol. 2008;3:774-80.

4. Takahashi M, Shigematsu Y, Ohta M, Tokumasu H, Matsukura T, Hirai T. Tumor invasiveness as defined by the newly proposed IASLC/ATS/ERS classification has prognostic significance for pathologic stage IA lung adenocarcinoma and can be predicted by radiologic parameters. J Thorac Cardiovasc Surg. 2014;147:54-9. 